\section{Design gráfico cambiante: a instabilidade como regra}

\begin{abstract}
RESUMO
0 artigo se propõe a identificar e analisar os fatores que dão condições para o surgimento do design gráfico cambiante. Para tanto, são pesquisadas as questões relacionadas à transição Modernidade / Pós-Modernidade e à história do design gráfico. 0 fenômeno do design gráfico cambiante é identificado e caracterizado através de manifestações que não adotam projetos de identidade visual estável, rompendo com os padrões e regras do design funcionalista do alto Modernismo. As variantes responsáveis pelo surgimento e crescimento da mutação de identidades no design gráfico são relacionadas à sociedade contemporânea, expondo 0 design gráfico cambiante como uma de suas faces.
\end{abstract}

\section{ABSTRACT}

This work aims at identifying and analyzing the main factors that have stimulated the appearance of a mutant graphic design. For that effect, it reflects upon the transition of Modernity to Postmodernity and upon the history of graphic design in general, specially from the Industrial Revolution onwards. The phenomenon of a mutant graphic design is identified and characterized with the help of examples which break with the habits and the rules of functionalist design of the Modernist school. The possible causes responsible for the appearance and development of a design philosophy which cultivates an unstable visual identity for graphic publications are related to social and cultural changes in contemporary society.

\section{PALAVRAS-CHAVE (KEY WORDS) \\ - Design gráfico (Graphic design) \\ - Modernidade (Modernity) \\ - Pós-modernidade (Post Modernity)}

\section{Rudinei Kopp}

Prof. Me. Dept. Com. Social da UNISC
Adjetivos como flexível, transitório, fugidio, cambiante, liqüefeito, fragmentado, entre tantos, têm servido para qualificar o tempo contemporâneo. O design gráfico reflete tudo isso como sua história recente demonstra. Sua condição num meio de caminho entre a indústria, a tecnologia, a arte, a cultura, o consumo e o público faz esse campo ser um espelho das transformações do cotidiano da sociedade. Se até nossa identidade cultural pode ser cambiante, sem um lastro crível como se acreditava até poucas décadas (ou anos), não representa uma surpresa tão grande percebermos que a indústria tem uma produção flexibilizada, pronta para se reprogramar facilmente, ou ainda, que os tão conhecidos projetos gráficos fixos não simbolizem mais a quintessência do design gráfico.

Enquanto existe distinção entre o que é moderno e pós-moderno nos sentimos "tranqüilos". Conseguimos administrar categorias. No design gráfico essas distinções costumam apelar para os estereótipos de cada época. O design moderno é assimétrico, retangular, administrado pela grade, usa tipos sem serifas, hierarquiza informações, tem a legibilidade como objetivo principal. O pósmoderno é eclético, redescobre elementos do passado, inclui o ruído, privilegia a atitude em detrimento da informação, é mais caótico e menos ordenado.

E um tipo de prática que transita entre esses dois extremos, abarcando todas as possibilidades, como se chama? É modernista por romper com as práticas anteriores, com ao antigo? É 
pós-modernista por ser plural, sincrético, mestiço?

Esse design que percorre desde o De Stijl até o Retro, por exemplo, proponho denominar como 'design gráfico cambiante'. $O$ adjetivo 'cambiante' tem origem no termo cambiare, do latim tardio. E o radical camb é de origem celta e significa 'arqueado, curvo', 'alternado, trocado'. A evolução do radical celta para a palavra latina, e do latim para o português, gerou o verbo 'cambiar', que se refere a 'trocar', 'transformar, alterar' (Cunha, 1986, p. 143). Cambiante é então aquilo que varia, que troca, que não é fixo, que barganha, que se transforma. A palavra 'cambiante' é recente na língua portuguesa, foi acrescentada ao nosso vocabulário em 1813 como registra Cunha (1986). O design gráfico cambiante pode ser compreendido também como um design mutante ou flexível. Ambos adjetivos se enquadram na proposta aqui apresentada.

Essa categoria de design também é uma manifestação da Pós-Modernidade. Não está arraigado a algum PósModernismo, tampouco, a Modernismos. Usufrui dos seus estilos e das suas técnicas, sem se identificar por longo tempo com cada um.

O design gráfico, historicamente, começa a privilegiar a repetição à medida em que algumas práticas são adotadas na área. Tomemos como exemplo as capas das revistas Jugend, Ver Sacrum, Harper's Bazar, Vogue e Life. Elas não apresentam uma fixidez de padrão visual. Cada edição é uma nova combinação de imagens, tipos e cores. Esse modo de trabalho é "normal" até os anos 1940. A partir de então, a padronização e a repetição de elementos começa a se tornar a nova prática "normal".

A mutabilidade do design passa a ser vista como antiga, ineficiente, instável, desordenada, irracional, ou seja, não apropriada ao mundo modernista dos racionalistas e funcionalistas. O Modernismo romântico e simbólico não estava de acordo com as linhas de montagem, com a indústria fordista e taylorista, não era útil ao progresso.

O design gráfico torna-se serializado e privilegia métodos que facilitem a reprodução. A década de 1940 é assolada pela Segunda Guerra e pela divisão do mundo em dois grandes blocos. Isso potencializa a adoção de medidas claras e bem definidas em todos os segmentos da sociedade. Os mundos capitalista e comunista são mantidos pela indústria e sua lógica da produtividade. As tensões entre capitalismo e comunismo provocam revoluções e insatisfações internas, e os sistemas políticos, econômicos e culturais começam a ser contrariados, contestados e questionados, principalmente a partir de 1968. O início da década de 70 é marcado pelas reações contra a dureza imposta durante o alto Modernismo, um período em que, mais do que nunca, a Modernidade deixou de se questionar e de se renovar.

O design gráfico espelhava essa sociedade, tanto através do estilo unificado da Escola Suíça, quanto por meio dos movimentos alternativos (revivalismo, vernacular, psicodélico, punk, new wave, entre outros). Richard Hollis destaca um novo momento do design gráfico no ano de 1974. Uma inovadora agência da Alemanha, a GGK, criou um "logotipo transmutável" para o Jornal Literatur in Köln, o "Lik" (Fig. 1) (Hollis, 2001, p. 218-219). Não dá para afirmar se esse é o instante em que uma estética cambiante retorna ao design, mas em termos de registro é representativo. Nessa mesma época, os projetos de relevância internacional eram os programas rígidos de identidade visual para empresas/ eventos como a Mobil (1965), Olivetti (1970) e os Jogos Olímpicos de Munique (1972), só para citar alguns.

\section{Lik SiK LiK LAK Li站 LiK LidX LiK 20 iK}

Fig. 1: Helmut Schmidt-Rhen,logo "transmutável" do Literatur in Köln, criado, 1974 (Fonte: Hollis, 2001, p. 218). 
Seguindo esse método, vamos enumerar alguns casos que se enquadram como design gráfico cambiante. $\mathrm{O}$ trabalho para o "Lik", nesta pesquisa, inaugura, ou reinaugura, a prática mutante no design gráfico. No entanto, sua projeção é muito restrita e não há segurança (e nem teríamos como pretendê-la) para saber se essa técnica não foi empregada noutros momentos e locais. O caso da MTV Music Television é conhecido de todos e representa uma postura diferente sob todos os aspectos, desde a segmentação de público até a identidade flexível da marca.

\section{Music Television}

Em 1981, a MTV(Music Television) entra no ar nos Estados Unidos. A idéia de lançar uma televisão que transmitisse uma programação voltada para música e o público jovem (videoclipes e programas afins) necessitava de idéias novas em todos os sentidos. Um estúdio de design de Nova lorque - o Manhattan Design - é contratado para desenvolver a identidade visual da nova emissora. A primeira sugestão do estúdio é mudar o nome de "The Music Channel" para "Music Televison". A partir disso é desenvolvido então o logo.

A base da marca é composta por um "M", com tipo sem serifa, tridimensional, e o "TV" sobreposto com uma letra "grafitada", com aspecto rústico e manuscrito.

Até este momento não há nada de inteiramente novo em termos visuais. Porém, a estratégia de uso é que irá provocar uma nova percepção.

O momento do insight ocorreu quando os designers realizaram o logo com um vasto conjunto de superfícies para o $\mathrm{M} \mathrm{e} \mathrm{o}$ vigoroso tv, podendo ser alterado através de infinitas variações de cor, decoração, materiais, três dimensões, ângulos de visão e movimento. Ele pode tornar-se muitos objetos - um bolo de aniversário, uma embalagem de comida chinesa, um bloco de gelo. O logo pode assumir diferentes personalidades, participar de animações, assim como pode ser demolido. $O$ conceito de um logo com constantes alterações é contrária a segura e ampla crença que marcas e identidades visuais devem ser fixadas absolutamente e usadas de modo consistente. Uma vez esse conceito decidido, o Manhattan Design produziu centenas de esboços para mostrar as possíveis variações (Meggs, 1998, p. 389) (Fig. 2,3 e 4).

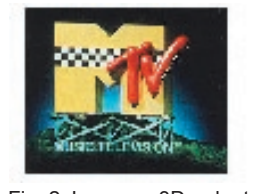

Fig. 2: Logo em 3D, adap do ao ambiente, 1981.
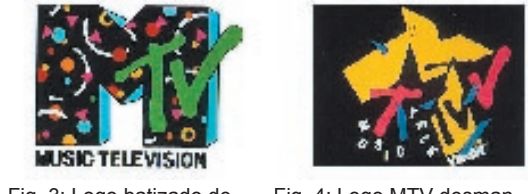

Fig. 4: Logo MTV desmanchando: versão "puzzle", "colorforms", 1985. 1985.

Meggs relata que a MTV obteve, em menos de vinte anos, um reconhecimento da marca somente inferior ao da Coca-Cola (Meggs, 1998, p. 389). Esse desempenho está ligado ao fato de a emissora ter detectado que o público jovem, composto por adolescentes principalmente, é mais facilmente propenso a alteridade. $O$ novo, o diferente, o que se altera e alterna, o zapping, compõem sua linguagem visual.

E. Ann Kaplan (1993) entende que a MTV é uma "torrente de significantes embaralhados e febris para os quais nenhum significado é pretendido ou tem tempo de ser comunicado" (Ann Kaplan, 1993, p. 53). A estratégia adotada pela MTV compreende que se comunicar com seu público é fazer transitar um número maior possível de imagens, a significação decorre, justamente, da quantidade. As imagens isoladas não tem tanta importância quanto o seu conjunto. Segundo Ann Kaplan "fica-se extasiado com as dimensões visuais e auditivas, que suplantam todas as demais. Deixa-se em suspenso a busca de um significado e fica- 
se absorto nas superfícies/texturas/formas/ sons que dominam os canais de recepção" (Ann Kaplan, 1993, p. 53).

Contemporânea à criação da MTV, outra empresa nasce sob a égide da fragmentação e da flexibilização da imagem: é a marca de relógios suíça Swatch. Combinando tecnologia industrial e ousadia no plano comercial, a Swatch é mais um símbolo da Pós-Modernidade.

\section{Relógios Swatch}

A Swatch não é um caso exclusivo de design gráfico, mas torna visível a adoção de uma estratégia de flexibilização num campo, reconhecidamente, conservador: os relógios suíços.

O caso dos relógios Swatch chama atenção por dois fatores: a revolução tecnológica, em nível técnico, que a marca liderou no início dos anos 80 e a nova estratégia mercadológica, adotando uma gama diversificada de modelos à disposição do consumidor.

A indústria suíça apostou naquilo que pode ser considerado a antítese das idéias que possuímos sobre relógios suíços.

Dearlove e Crainer (2000) destacam que "ao contrário dos antigos relógios suíços, esse não seria passado de pai para filho, mas era a última palavra em relógios descartáveis.

Os consumidores eram convidados a jogar seu velho Swatch e comprar outro" (Dearlove \& Crainer, 2000, p. 155).

$\mathrm{O}$ design dos relógios tornou-se o principal atrativo dos produtos (Fig. 5). No início, a Swatch renovava suas coleções a cada seis meses.

Com o tempo, essa renovação foi se tornando mais freqüente, e os consumidores adotaram o Swatch como uma segunda marca de relógio, ou ainda, como adereço descontraído e divertido no visual cotidiano.
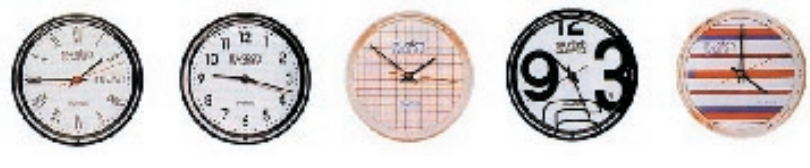

Fig. 5: Modelos da primeira coleção (1983). As variações não são

a preocupação mais com 0 ainda muito radicais, mas já se percebe orginal do relógio: marcar as horas do Bertoni in Barata et al, 1993, p. 204).

4 Projetos gráficos cambiantes

O desenvolvimento de revistas, especialmente a partir da década de 1940, incorpora uma nova preocupação. Até então, a adoção de um projeto gráfico que disponibilizasse de uma gama finita de recursos para o layout das páginas não era uma prática hegemônica.

A maioria das revistas passa a determinar alguns componentes visuais mínimos que se repetem de um número para o outro. Geralmente, o nome da revista, através de seu logo, é o elemento mais estático. A estratégia mais usual é determinar um lugar e um tamanho específico para esse logo. As variações ficam, quando acontecem, por conta da alteração de cor para se adaptar ao restante da capa, e às vezes, varia-se a localização do logo. Algumas publicações possibilitam a rotação do título.

Ou ainda, viabilizam a opção do logo proporcionar uma idéia de profundidade, ou seja, colocando pessoas ou objetos sobre as letras de tal forma que o fundo da imagem pareça estar localizado num plano mais distante em relação a pessoa ou objeto e ao próprio logo da revista. A questão dos tipos também é um quesito fundamental. É normal uma revista não repetir as mesmas fontes tipográficas de uma capa para outra, conferindo um ar de novidade não só através da imagem principal, mas também através de desenhos diferenciados para a mensagem verbal .

Outra opção de alteração entre um número e outro é mudar o formato ou tamanho da revista. A Colors, da Benetton, 
em suas doze primeiras edições apresentou dimensões variadas. A Shift é mais radical na sua proposta e, além de trabalhar com dimensões flutuantes, apresenta formas de montagem, materiais e suportes diferenciados. A Shift número 2 tinha como tema 'carne' e a forma de união das páginas era através de um furo em todas as páginas, e o que as mantinha "unidas" era um gancho de açougue. O tema da Shift número 8 é 'jogos', suas páginas são como cartas de baralho e a "capa" imita uma lancheira feita em plástico.

Internamente, as publicações impressas têm a tendência de acompanhar o design das capas. Não pretendemos nos alongar neste item, até porque as possibilidades de design no tocante à diagramação de várias páginas é bem mais ampla, e seu registro histórico mais deficitário nas referências bibliográficas disponíveis.

As revistas possuem um comportamento visual "naturalmente" variável. Contudo, o que estamos denominando como design gráfico cambiante extrapola a simples alteração de um item ou outro. O cambiamento de combinações visuais nos periódicos: Ray Gun, Big, Matiz e Sexta-Feira, envolve o material de modo amplo.

\subsection{Ray Gun}

A revista norte-americana Ray Gun começou a circular em 1992. Tendo como linha editorial a rock music, o periódico se dispunha, desde o início, a oferecer um produto diferente para o seu público. Para o desenvolvimento do design gráfico foi contratado David Carson. Com a liberdade que lhe foi proporcionada e a opção por um "design de atitude", Carson explorou ao máximo a quebra de regras.

A legibilidade foi considerada tarefa menor. As capas da revista exploram: letras feitas a mão (Fig. 9 e 13); fotos de má qualidade (para os padrões gráficos usuais)
(Fig. 11); tipos distorcidos, recortados, quebrados e recombinados (Fig. 7 e 9); sujeira, ruído e rabiscos como "ornamento" (Fig. 6 e 14); sobreposições de imagens (feitas no Photoshop - software para tratamento e manipulação de imagens) (Fig. 12); espaçamentos irregulares e irracionais (entre-linhas e kernings - espaço entreletras - que "prejudicam" a leitura) (Fig. 11); inversão hierárquica das informações (o código de barras com mais ênfase que a fotografia da banda entrevistada) (Fig. 13); além de uma série de experimentos visuais que representam uma nova proposta em design gráfico. $\mathrm{O}$ interior da revista, da mesma forma que suas capas, não obedece parâmetros que privilegiem a leitura.

Os dois primeiros números da Ray Gun mantiveram um logo igual nas suas capas (Fig. 6 e 7). Posicionados no mesmo lugar, com as mesmas proporções e com o mesmo tipo. Esse plano, no entanto, já é abandonado a partir do número 3 (Fig. 8). $\quad O$ design não se repetirá mais desde então, cada edição será uma nova combinação, uma nova percepeção, um significante renovado.

A capa torna-se, juntamente com todo o trabalho nas páginas internas, um signo de alteridade. Procura falar a seu público de maneira inquietante. A Ray Gun e seu cambiamento de ilustrações, textos e fotos procura satisfazer o ritmo de sons e imagens que a televisão oferece.

Na Ray Gun as palavras falam menos que o design, para ler suas matérias é necessário traduzi-las.

De acordo com Michel Maffesoli (1995), essa profusão de imagens faz com que ela seja consumida no seu instante, no aqui e agora. "Serve de fator de agregação, permite perceber o mundo e não representá-lo." Seu caráter mitológico, que requer a decifração dos signos, "une entre si os iniciados"'(Maffesoli, 1995, p. 35).

Ser um iniciado ou fazer parte desta ou daquela "tribo", compreende a 
capacidade de se identificar com a imagem que não se cristaliza, que constantemente se torna outra, que não é definida, que hoje prefere Marilyn Manson e amanhã R.E.M. A inconstância das capas e páginas repete a seqüência de imagens dos frames sobrepostos uns aos outros no videoclipe.

A sucessão de significantes com pouca ou nenhuma relação entre si, e que isolados parecem incoerentes ou com significado deslocado (sem referência com o todo), tem valor apenas como sucessão, como enxurrada. Interessa produzir e consumir o maior número possível de significantes, eles só significam enquanto se sobrepõem.

Capas da Ray Gun

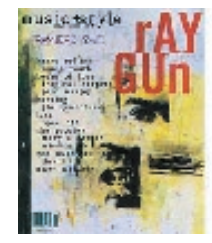

Fig. 6: RG 1/1992 9: RG 6/1993

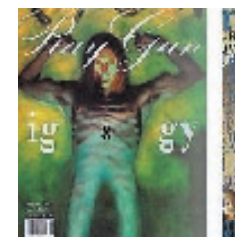

Fig. 10: RG 8/1993 13: RG 19/1994

\subsection{Big}

A revista Big é publicada em vários países do mundo e sua estratégia é ser multicultural. As edições são temáticas, cada número privilegia uma questão e trata, geralmente, esse assunto com uma abordagem não-convencional. As fotografias são beneficiadas e é normal a publicação apresentar, em termos proporcionais, muito mais imagens fotográficas do que texto ou qualquer outro tipo de informação verbal.

A Big parece desejar "apagar o tempo", não existe nenhuma referência aos períodos (ano ou mês) de suas edições em parte alguma da revista. Ela é editada em New York e impressa na Espanha.

Analisar visualmente a Big só é possível em seu conjunto. Poderíamos, facilmente, tomarmos a capa de uma edição (Fig. 16) e julgarmos como o emprego de um 'design moderno'. Esse posicionamento, no entanto, não condiz com a postura visual da revista como um todo.

Até a número 25 (Fig. 14) o periódico mantém o uso constante de um logo. As alterações da marca são pequenas de uma edição para outra. O tipo utilizado até a 25 também é o mesmo, alguma fonte tipográfica derivada da Helvética (provavelmente a Swiss). A posição, o tamanho e a cor se alteram, mas a identididade visual se mantém, sendo possível reconhecer a revista através do seu logo. A número 28 (Fig. 15) rompe com esse planejamento e troca o tipo sem serifas por uma com serifas.

A número 31 (Fig. 17) usa uma fonte serifada também, porém de outra família tipográfica. As alterações se sucedem e não há mais repetição de logo.

O design das capas é minimalista e até austero às vezes. Contudo, a nãofixidez e a flexibilidade do material tornam a Big um exemplo de design gráfico cambiante. De fluxo de combinações nãorepetitivas.

Cada Big é "coerente" isoladamente, ou seja, ela adota um projeto gráfico para um número e segue, desde a capa até a diagramação dos textos internos. No próximo número tudo é feito diferente.

As equipes que trabalham na edição de cada revista são alteradas. Repórteres, fotógrafos e designers são trocados e dessa forma uma nova percepeção é oferecida ao leitor.

Por exemplo, a número 257(Fig. 14) foi desenhada por Rico Lins e a número 34 (Fig. 20) por Renata Zincone (só para ficarmos nas edições dedicadas ao Brasil).

Capas da Big 

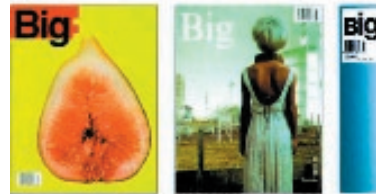

Fig. 14: Bign 27 Fig. 15: Big no $28 \quad$ Fig. 16: Bign $n^{0} 30$ Fig. 18: Big n 32
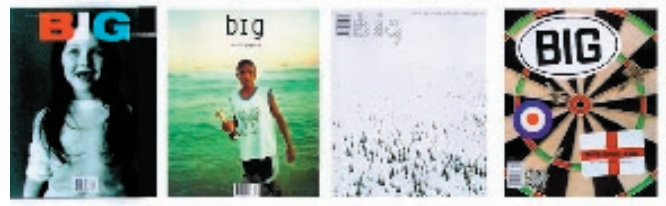

Fig. 17: Big nº 31

Fig. 19: Big n⿳⺈ 33 Fig. 20: Big no 34 Fig. 21 Big n $^{0} 35$

Fig. 22: Big nº 36 Fig. 23: Big $n^{\circ} 37$

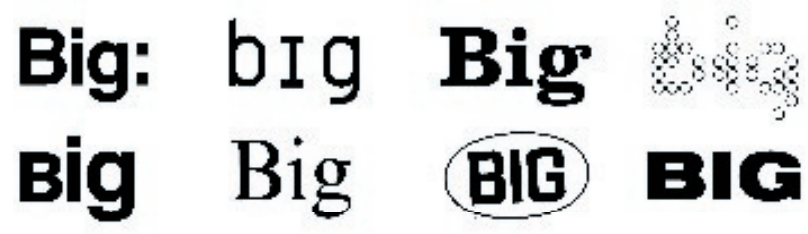

Fig. 24: Variações do logo "Big"

\subsection{Matiz}

A Matiz surgiu em 1997, no México, com o intuito de reunir numa revista trabalhos, matérias, artigos, discussões e entrevistas relacionados com o design gráfico do México, especialmente, além de outros países. A proposta visual da Matiz é não repetir suas capas, experimentando a cada número novas possibilidades visuais e técnicas. As páginas internas são, da mesma forma, um conjunto de ensaios gráficos que não solidifica um projeto. No mesmo número, por exemplo, um artigo é desenhado de uma forma, enquanto a matéria a seguir possui outra combinação bem diferente. A tipografia dos textos longos costuma manter-se a mesma, uma família sem serifas (uma espécie de mistura entre Gill Sans e Helvética).

As capas da Matiz possuem seu logo incorporado ao restante do layout, desde o aspecto temático até sua imbricação visual com os demais elementos gráficos. A Matiz lança mão de vários expedientes para compor seu logo e suas capas. Os logos podem ser montagens geométricas, utilizando apenas linhas retas e fragmentos de círculos perfeitos, dando um aspecto de pedaço de máquina (Fig. 25); podem ser minimalistas como os tipos do De Stijl, usando somente ângulos em noventa e zero graus (Fig. 26); utilizar letras cursivas (Fig. 27); tipos sem serifa todo em minúsculas e com entre-linhas ampliado (Fig. 28); tipos à moda Edward Fella (Fig. 29); escrita de traços geométricos em maiúscula (Fig. 30); tipos híbridos que lembram letras góticas antigas (Fig. 31); letras desconstruídas com espaçamento irregular num estilo muito semelhante ao de David Carson (Fig. 33.

A Matiz se reinventa graficamente a cada edição. Assim como o público da Ray Gun, identificado com a alteridade e com a linguagem dos videoclipes, o público da Matiz é propenso ao consumo de uma miríade de imagens. A revista se destina a profissionais e pessoas ligadas ao ramo do design gráfico. Dessa forma, sua atitude é vista como uma transformação do meio impresso num canal de experiências visuais e circulação de significantes. Faz sentido ao designer, ou a profissionais das artes e comunicações visuais, o "despejo" de várias técnicas, recursos e experimentos gráficos.

\section{Capas da Matiz}
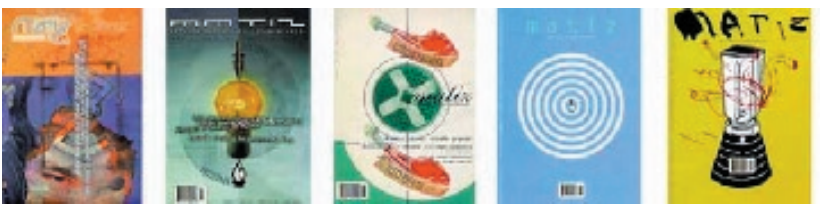

Fig. 25: Matiz no $1 / 1997$ Matiz no $7 / 1999$

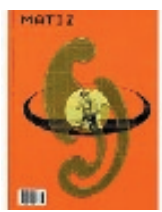

\section{Fig. 30:}

Matiz n $8 / 1999$ Matiz no 19/2000

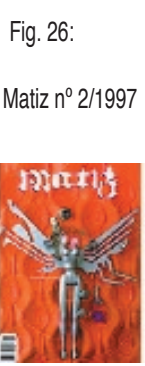

Fig31:

$\begin{array}{ll}\text { Fig31: } & \text { Fig. 32: Fig. 33: } \\ \text { Matiz n } 16 / 1998 & \text { Matiz } n^{\circ} \text { 17/1999 }\end{array}$ Fig. 27: Fig. 28:

Matiz n ${ }^{0} 5 / 1997 \quad$ Matiz $n^{0}$ 6/1999

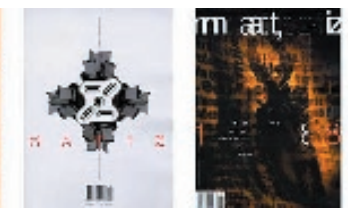

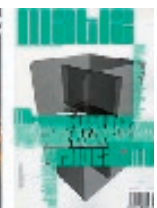

Fig. 34: Matiz nº 18/1999

\subsection{Sexta Feira}

A revista Sexta Feira - editada pelo Departamento de Ciência, Antropologia e 
Humanidades da USP (Universidade de São Paulo-SP) - tem um projeto gráfico que contraria a austeridade da maioria das revistas científicas. A opção por uma estética cambiante confere à publicação a inovação contínua de número para número, de página para página.

As edições são temáticas (Festas, $n^{\circ}$ 2; Fronteiras, $n^{\circ} 3$; Corpo, $n$ 4; Tempo, $n^{\circ} 5$ ) e o tratamento visual procura acompanhar essas variações. Na edição sobre o corpo (Fig. 37), por exemplo, a imagem da capa destaca um objeto de couro sobre a palma da mão. As cores e traços são semelhantes entre objeto e mão. Há uma espécie de simbiose entre o corpo e o objeto.

A segunda edição da revista usa a foto de uma festa popular com o vermelho predominando (Fig. 35); a terceira é uma textura indefinida em verde e preto (Fig. 36); a quarta é uma fotografia em closeup (Fig. 37); e a quinta é um pedaço de uma foto atravessada por um tarja preta na vertical (Fig. 38). Isso demonstra as variações empregadas para o desenho das capas. O elemento que se mantém estável é o uso do título da revista em minúsculas. Quanto a posição do logo e a tipografia não há nenhum critério adotado. A localização percorre vários pontos e se posiciona com ângulos diferentes.

$\mathrm{Na}$ parte de dentro a oscilação de recursos permanece. Na mesma revista não existe elo visual entre matérias consecutivas. As fontes tipográficas são alteradas, assim como as colunas, fios e posição das ilustrações e fotos. A Sexta Feira varia até mesmo os tipos de papéis utilizados dentro da mesma edição. A número 3 possui páginas em papel fosco e poroso (sulfite) de tonalidade verde intercalado com páginas em papel couchê brilhante.

\section{Capas da Sexta Feira}
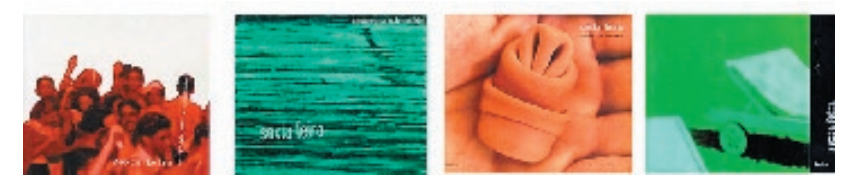

Fig. 35: $\quad$ Fig. 36: $\quad$ Fig. 37: $\quad$ Fig. 38:

Sexta Feira n ${ }^{0}$ 2/199 Sexta Feira $n^{0}$ 3/1998 Sexta Feira no 4/1999 Sexta Feira n $5 / 2000$

Festas Fronteiras Corpo Tempo

Conseguimos identificar algumas manifestações do design gráfico cambiante. Sabemos que os exemplos exibidos não contemplam a amplitude do fenômeno, contudo, servem como comprovação e material de análise para tentar identificar os elementos que dão condições para o surgimento dessa prática: o design gráfico cambiante.

\section{Considerações finais}

"Mas os elos não retinham, e de seus braços e pernas as hastes de vime caíam longe dele." (Hino Homérico a Dioniso I, 13-14)

Zygmunt Bauman (2001) trabalha com denominações diferentes em relação a questão da Pós-Modernidade mas sua percepção do estágio contemporâneo revela os principais contornos do que representa a mudança epistemológica que viemos atravessando desde, principalmente, a década de 1970. "Se a modernidade sólida punha a duração eterna como principal motivo e princípio de ação, a modernidade "fluida" não tem função para a duração eterna. O "curto prazo" substituiu o "longo prazo" e fez da instantaneidade seu ideal último" (Bauman, 2001, p. 145).

O período de 1965 a 1973 mostra a incapacidade do fordismo e do keynesianismo sustentarem as contradições do capitalismo. A rigidez a que havia chegado as atividades ligadas ao capital fixo, não acompanhava mais as variações do mercado, o fluxo de capitais e as relações trabalhistas. David Harvey (2000) chama de acumulação flexível a nova forma de relação entre o setor industrial, o mercado e a força trabalhista. "Ela se apóia na flexibilidade dos processos de trabalhos, dos mercados de trabalho, 
dos produtos e padrões de consumo" (Harvey, 2000, p. 140).

A transição de um modelo que tende ao durável para outro que é flexível, anuncia novos adjetivos para o seu tempo. "A estética relativamente estável do modernismo fordista cedeu lugar a todo fermento, instabilidade e qualidades fugidias de uma estética pós-moderna que celebra a diferença, a efemeridade, o espetáculo, a moda e a mercadificação de formas culturais" (Harvey, 2000, p. 148).

Os movimentos culturais da década de 1970 mostram, entre tantos, o poder de articulação feminina. O domínio masculino era questionado e a mulher passava a exigir seu lugar na sociedade como agente de igual valor ao equivalente masculino. Françoise Collin (1991) destaca que o movimento feminista objetivava a construção de um "espaço verdadeiramente comum aos homens e às mulheres" (Collin, 1991 , p. 346). Esses ideais crescem, e mesmo não tendo atingido os patamares sonhados, faz com a que a sociedade, hoje, seja menos masculina que em outros tempos. Collin lembra que, normalmente o "masculino se define pelo fálico, pelo uno, pela totalização, pela instrumentalização", enquanto o feminino "define-se pelo aberto, pelo não-uno, o infinito, o indefinido, a ilimitação" (Collin, 1991, 345). Seguindo esse pensamento, podemos dizer que a sociedade sendo mais feminina do que "antes" é mais propensa a alteridade, uma vez que é aberta, infinita e ilimitada.

Para Fredric Jameson (2000), as ondas de descolonização e liberação nacional dos anos 1960 e 70, criam "sujeitos individuais e genuínos que não estavam lá antes" (Jameson, 2000, p. 356), que eram invisíveis ou estavam sob tutela. Grupos identificados com modos diferenciados daqueles tidos como o padrão manifestam sua insatisfação com o status quo. Homossexuais, afro-descendenetes, ameríndios, imigrantes e mais uma quantidade inumerável de comunidades, freqüentemente, excluídas do centro das decisões ou das representações culturais oficiais se articulam para fazerem valer suas identidades. Essa movimentação provoca uma avalanche de identificações possíveis. Independente de terem alcançado um posto privilegiado ou não, forneceram, juntamente com o feminismo, opções de escolha ao sujeito. As identidades culturais solaparam a idéia de unidade em nome da identificação instantânea, conveniente, descontraída e por tempo indeterminado.

Afirmar em que proporção as relações econômicas estão relacionadas às manifestações culturais, ou ainda, quem determina quem, é um caminho perigoso. Nos basta aqui, detectar as variantes possíveis e interrelacionadas que se referem as alterações da nossa existência ao mesmo passo que a variação do modo de percepção.

A metade da década de 1980 inaugura a competição frenética da informática. O desenvolvimento de computadores pessoais provoca uma corrida pela atualização constante não vivida pelo homem até então. Equipamentos e programas são renovados em prazos de um ano a um ano e meio e desatualizam velozmente o bem adquirido há poucos meses. A flexibilidade é combinada com a capacidade de renovação constante, e gera um modo de consumo tecnológico que não se satisfaz em executar as tarefas que os equipamentos podem oferecer. Os sujeitos da época do up grade não aceitam o velho, ou seja, não se satisfazem com a versão 9.0 se já existe a 10.0. Urge ser atual, renovado e hodierno a qualquer custo.

Da mesma forma que os padrões de consumo são potencializados pela tecnologia, os modos de produção também. O computador pessoal juntamente com novas linguagens e programas, conseguiu devolver às mãos dos designers maior capacidade inventiva e de renovação. Alterar, completamente, um esquema visual é muito simples e rápido com os hardwares e softwares disponíveis a partir de 1985 (computador Macintosh da Apple, 
a linguagem PostScript e o programa de edição de página Page Maker).

De acordo com Guy Debord (1997), a renovação tecnológica incessante e o presente perpétuo não trazem benefícios ao homem. Debord acredita que "o indivíduo deve desdizer-se sempre, se desejar receber dessa sociedade um mínimo de consideração. Essa existência postula uma fidelidade sempre cambiante (...). Trata-se de correr atrás da inflação dos sinais depreciados da vida" (Debord, 1997 , p. 191) São sintomas dos tempos que Debord prenunciou em 1967 (ano do lançamento de La Société du spectacle - A Sociedade do espetáculo), uma época inflacionada pelo trânsito de sinais e pela efemeridade da vida cotidiana.

$O$ design espelha o contexto social no qual está inserido. Resultado da combinação entre técnicas artísticas, tecnologias de produção/reprodução e objetivos mercadológicos, o design gráfico é tão inovador ou retrógrado quanto a sociedade que representa. Quando a Modernidade estagnou, boa parte do design tornou-se fordista e cientificizado. Tal como o cão de Pavlov que ouvia a sineta e salivava de fome, sugere-se que a repetição de imagens (logos em revista por exemplo) nos induzam a uma relação lógica entre significante - o logo - e o significado - a revista propriamente dita. Essa prática tornou-se corrente, motivada por uma economia de tempo de produção e de estímulos. Da mesma forma que Jacques Derrida (1973) nos informa que a escritura é resultado da economia de tempo e espaço, devido, principalmente, ao grande volume de textos produzidos pelos filósofos. A adoção de padrões responde a critérios de otimização de tempo e resultado, tanto sob o aspecto industrial como sob o aspecto cognitivo. Quanto mais uma imagem fosse explorada e repetida, mais ela seria eficiente e funcional.

Assim como o Dada em meados da década de 1910, a Pop Art no princípio dos anos 1970 rompe com os paradigmas clássicos de arte. A distância entre o artista e o público é achatado, desde a questão da recepção até a produção. Isso quer dizer que a arte deixa de ser uma prática superior, acima da massa. As conhecidas 'instalações' contemporâneas são manifestações de arte que negam a permanência. São intencionalmente efêmeras, datadas. Nascem na mesma velocidade que desaparecem

$A$ adoção da unidade visual em design gráfico marca a entrada do alto Modernismo. Seu questionamento vem junto com as alterações na sociedade. As teorias pós-estruturalistas servem de incentivo às indagações sobre a neutralidade do design não-renovado, repetitivo e monótono do Estilo Internacional. Termos como acumulação flexível, pós-fordismo, fluxos econômicos instáveis e voláteis, relações empregatícias temporárias, identidades culturais cambiantes, desconstrução, feminismo, descolonização, movimentos sociais (negros, homossexuais, minorias étnicas e culturais etc), renovação tecnológica constante, consumismo, falência das metarrativas, são entre tantos, os motivadores de uma sociedade permeada pelo efêmero, instantâneo, transitório, flexível, plural, sincrético, superficial, mutável, cambiante, fluido, que assume as incertezas do futuro, não acredita nas grandes soluções, manifesta e assimila um número maior de vozes (no entanto, isso não significa, necessariamente, maior participação política ou econômica).

A estética cambiante que 0 design gráfico nos oferece atualmente pode não ser uma prática ou estratégia hegemônica. Não foi adotada por um grande número de designers ou empresas e tampouco sabemos se um dia isso acontecerá. O fenômeno é visível e vem crescendo como possibilidade no design gráfico atual. Os elementos que deram condições para o seu surgimento se confundem com a Pós-Modernidade e uma das faces desse tempo é o próprio design gráfico 
cambiante. Quanto ao fato da mutabilidade no design ser apenas o resgate de uma prática corrente até os anos 1930, não invalida o retorno dessa estratégia. $O$ princípio da originalidade é uma pretensão modernista e o cambiamento não está mais "naturalizado", ou seja, quando revistas como a Life, a Vogue e a Jugend, por exemplo, eram feitas não havia um momento anterior que imaginava a padronização como melhor opção para o design gráfico. A partir disso as opções passam a ser estratégicas e o cambiamento se mostra como recurso intencional. Seu trânsito constante de significantes procura significar algo através do conjunto. Procurar o significado isoladamente não revela mais do que o instante.

O design gráfico cambiante é dionisíaco. Assim como o deus grego Dioniso, suas definições nos escapam. Ele é polimórfico, morre e renasce várias vezes. É complexo e fugidio. Alain Moureau (in Pierre Brunel, 1998) não sabe como descrevê-lo físico ou psicologicamente. Suas várias faces (leão, bode, cabrito, urso, fantasma, touro, pantera etc.) e nomes (Dioniso, Zagreu, Baco, Baqueu, Lakco, Sabázio, Brômio etc.) não o definem como um deus uno. Suas representações em estátuas percorrem desde a imagem do menino de colo, passam pelo homem robusto até o sujeito afeminado de cabelos encaracolados. As metamorfoses de Dioniso servem de metáfora para o design gráfico que nega solidificar-se e não é retido por correntes ou amarras, que sempre renasce diferente. Saber se a imagem que cambia sem cessar é mais ou menos eficiente comercialmente, neste instante, não é tão revelador quanto perceber como os momentos de fluidez da sociedade podem, às vezes, ser melhor interpretados em capas de revista do que nas linhas longas e frias da academia teoricista e taciturna .
ANN KAPLAN, E. (org.) 0 mal-estar no pós-modernismo. Trad. Vera Ribeiro. Rio de Janeiro: Jorge Zahar, 1993.

BARATA, Martins et al. Design em aberto: uma antologia. Porto: Centro Português de Design, 1993.

BAUMAN, Zygmunt. Modernidade líquida. Trad. Plínio Dentzien. Rio de Janeiro: Jorge Zahar, 2001.

BUENO, Silveira. Grande dicionário etimológico e prosódico da língua portuguesa. Vol. 4. São Paulo: Saraiva, 1965.

BLACKWELL, Lewis. The end of print: the graphic design of David Carson. San Franscisco: Chronicle Books, 1996.

CAUDURO, Flávio V. "A retórica tipográfica do logocentrismo". In: Estudos em Design, vol. 9, n.1/2, out. 2001, Rio de Janeiro. pp. $69-76$

COLLIN, Françoise. "Diferença e diferendo: a questão das mulheres na filosofia". In: THÉBAUD, Françoise. História das mulheres: 0 século XX. Vol. 5. Trad. Alda Maria Durães et al. Porto: Afrontamento, 1991. pp. 315-349

CRAINER, Stuart \& DEARLOVE, Des. 0 livro definitivo das marcas. Trad. Maria Lúcia G. L. Rosa. São Paulo: Makron Books, 2000.

CUNHA, Antônio Geraldo da. Dicionário etimológico Nova Fronteira da língua portuguesa. 2a. ed. Rio de Janeiro: Nova Fronteira, 1986.

DEBORD, Guy. A sociedade do espetáculo. Trad. Estela dos Santos Abreu. Rio de Janeiro: Contraponto, 1997.

DERRIDA, Jacques. Gramatologia. Trad. M. Schnaiderman e R. J. Ribeiro. São Paulo: Perspectiva, 1973.

HALL, Stuart. A identidade cultural na pós-modernidade. Trad. Tomaz Tadeu da Silva e Guacira Lopes Louro. 3. ed. Rio de Janeiro: DP\&A, 1999.

HARVEY, David. A condição pós-moderna: uma pesquisa sobre as origens da mudança cultural. 9. Ed. Trad. de Adail U. Sobral e Maria S. Gonçalves. Loyola: São Paulo, 2000.

HELLER, Steven. Graphic style: from Victorian to Post-

Referências 
Modern. New York: Harry N. Abrams, 1988.

HOLLIS, Richard. Design gráfico: uma história concisa. Trad. Carlos Daudt. São Paulo: Martins Fontes, 2001.

JAMESON, Fredric. Pós-Modernismo: a lógica cultural do capitalismo tardio. Trad. Maria E. Cevasco. 2. ed. São Paulo: Ática, 2000.

JENCKS, Charles. What is post-modernism? 4. ed. Bafins Lane: Academy, 1996.

KUMAR, Krishan. Da sociedade pós-industrial à pós-moderna: novas teorias sobre o mundo contemporâneo. Trad. Ruy Jungmann. Rio deJaneiro: Jorge Zahar, 1997.

LATOUR, Bruno. Jamais fomos modernos. Trad. Carlos Irineu da Costa. Rio de Janeiro: Ed. 34, 1994.

LESLIE, Jeremy. Nuevo diseño de revistas. Trad. Joan Escofet e Camila Enrich. México: Gustavo Gili, 2000.

LYOTARD, Jean-François. A condição pós-moderna. Trad. Ricardo Corrêa Barbosa. 5. ed. Rio de Janeiro: José Olympio, 1998.

MAFFESOLI, Michel. A contemplação do mundo. Porto Alegre: Artes e Ofícios, 1995.

MEGGS, Philip B. A history of graphic design. 3. Ed. New York: John Wiley \& Sons, 1998.

"The Politics of Style". In: BIERUT, Michel et al. Loking closer 2: critical writings on graphic design. New York: Allworth, 1997. pp. 53-55.

MOREAU, Alain. Dioniso antigo, o inatingível. In: BRUNEL, Pierre (org.) Dicionário de mitos literários. Trad. Carlos Sussekind et al. 2. ed. Rio de Janeiro: José Olimpyo, 1998. pp. 239-248. 